\title{
Miniaturized Automated Color Sorting System using Programmable Logic Control and Web-based Server
}

\author{
Edward A. Castillo \\ Electrical and Computer \\ Engineering \\ The University of Texas \\ at San Antonio \\ San Antonio, TX, USA
}

\author{
Sheng-Jen Hsieh, PhD \\ Engineering Technology \& \\ Industrial Distribution and \\ Mechanical Engineering \\ Texas A\&M University \\ College Station, TX, USA
}

\author{
Yunyi Wang \\ Department of Mechanical \\ Engineering \\ Texas A\&M University \\ College Station, TX, USA
}

\begin{abstract}
As technology advances, industrial companies and their systems need to be able to adapt swiftly when it comes to rapid production changes to meet the market needs of today for innovative products. Majority of automated industrial systems are controlled with programmable logic controllers (PLCs) that are programmed with ladder logic. With the incorporation of internet control using a Web-Based server to command and control a PLC for an industrial system, great advances can occur due to the internet being an increasable and an important intermediate for distributing information through the World Wide Web. By controlling and commanding a machine from a remote location through a Web-Based server, operating and observing the system can become cheaper and trouble-free. The focus of this study was primarily to construct a miniaturized automated color sorting system to be controlled by a PLC trainer set in order to determine how well a Web-Based server will do with the incorporation of a PLC. Future works include the comparison of the current Web-Based Server that was developed against a different type of Web-Based Server.
\end{abstract}

\section{Keywords}

Programmable Logic Controllers, Color Sorting, Web-Based Server, Automated Systems.

\section{RESEARCH OBJECTIVE}

The focus of this study was primarily to construct a miniaturized automated color sorting system to be controlled by a PLC trainer set in order to determine how well a WebBased server will do with the incorporation of a PLC. The objective of this system was to create a continuous system by sorting colored marbles (RGB) into groups by their color then randomizes the output before being fed as a new input for the system. The type of Web-Based server plays a great role in the overall productivity of an industrial system due to the connection speed between the Web-Based server and the PLC. A Web-Based server using Apache, HTML, PHP Script, VB application, and a Web-cam Server were used for this research. In future research, comparison of another WebBased Server will be used which will be developed from Information Servers (IIS) with an Active Server Page (ASP) to determine the overall performance between these two WebBased Servers.

\section{INTRODUCTION}

\subsection{Programmable Logic Controllers}

Majority of today's automated industrial systems are controlled with programmable logic controllers (PLCs). These PLCs are programmed using ladder logic. PLCs are a microprocessor based control system that can be programmed to sense, activate and control industrial equipment which has been made possible with the incorporation of number of inputs/outputs terminals for interfacing to an industrial process [7]. These PLCs are the brain of machine controlling by using a controller operating cycle. These controller operating cycles typically include input, program, and output scans in order to keep the operating cycle in motion. As technology advances, industrial systems need to be able to adapt swiftly when it comes to rapid production changes to meet the market needs of today for innovative products. Since PLCs are used widely for managing discrete processes, using a Web-based sever could provide great advances since the internet is an increasable and important intermediate for distributing information worldwide [3]. By controlling and commanding an industrial system in a remote location through the internet, productivity for industrial companies can dramatically improve.

\subsection{Color Sorting Industrial Systems}

One of the many processes in industrial systems are color sorting. Current methods for color sorting include real time image processing hardware which requires lighting conditions to remain reasonably [1]. Other industrial applications use certain controllers such as a Mitsubishi FX $2 \mathrm{~N}$ series PLC. This PLC has excellent machine control capabilities with color sensing for a color sorting system [5]. Infrared sensors can also be used to sense colors of a body based on its reflectivity. A color sensor can be very effective and useful as seen in [5]. In order for color sorting systems to be beneficial to an industrial company and improve overall production, these systems need to be precise and dependable to separate objects in different color groups. In addition, these systems need to be easy to operate by company employees and meet the requirements of productions for the company [1]. The use of a color sorting system in a manufacturing process can increase accuracy in sorting which can cause an improvement in productivity.

\subsection{Web-Based Server Controlling Industrial Systems}

Current methods for internet controlled automated system included, but not limited to, the use of Supervisory Control and Data Acquisition (SCADA), Decentralize Software Services (DSS), PCs connecting to PLCs through hubs, user interface using Microsoft Internet Explorer and LAN line control, computer network services, and Visual Studio with ASP NET [2] [4] [6] [7]. These methods can provide industrial companies easy access to their automated systems where they can be controlled at any time and any location. Using one of these methods could cut down maintenance and other costs for an industrial company. The use of the World 
Wide Web to control systems has increased dramatically over the years. This is evident by observing large industrial companies' manufacturing processes such as General Motors and the Oil and Gas industry [8]. The use of the internet is not very common with small scale companies compared to the larger ones, but these types of methods are progressing. Since PLCs are used for flexible manufacturing systems, material handling systems, and transfer lines, using some type of internet control could be very beneficial to an industrial company [3].

\section{METHODOLOGY}

\subsection{Programmable Logic Controller Trainer Set}

To provide more research in development in reliable real time monitoring and control systems using the internet, a PLC trainer kit and a miniaturized automated color sorting system needed to be developed. The introductory research required construction of a PLC training set using an Allen-Bradley Micrologix 1000 PLC, a 128 VAC to 24 VDC Converter, a 24 VDC to 9 VDC Converter, a ribbon cable, a power socket, a switch, plexiglass, two hinges, a 8.5 " x 13 " x 5 " black box to contain these items and the miniaturized system. One half of the black box will hold these materials while the other half will take the place of an 8.5 " x 5 " x 5 " system. In order to power the Micrologix 1000 PLC, 24VDC was used. To power the outputs of the system, 9VDC were needed. This PLC cannot detect any inputs that are powered with any voltage below 14 volts thus, the reason for the 128 VAC to 24 VDC converter. The outputs of the system on the other hand can be any voltage. In order for these items to stay secure to the inside of the black box, Velcro strips were used. Over the PLC and power sources, a sheet of plexiglass was used as a door to cover these items. The hinges were used to secure the plexiglass door to the inside of the black box. This plexiglass had cut outs in order to insert a switch, a power socket, and a space to connect the communication cable for the PLC. The switch was used in order to energize the PLC off and on whenever the user would use the trainer kit. The ribbon cable was used to communicate with the system that was built later on. In Figure 1, the PLC trainer set can be seen.

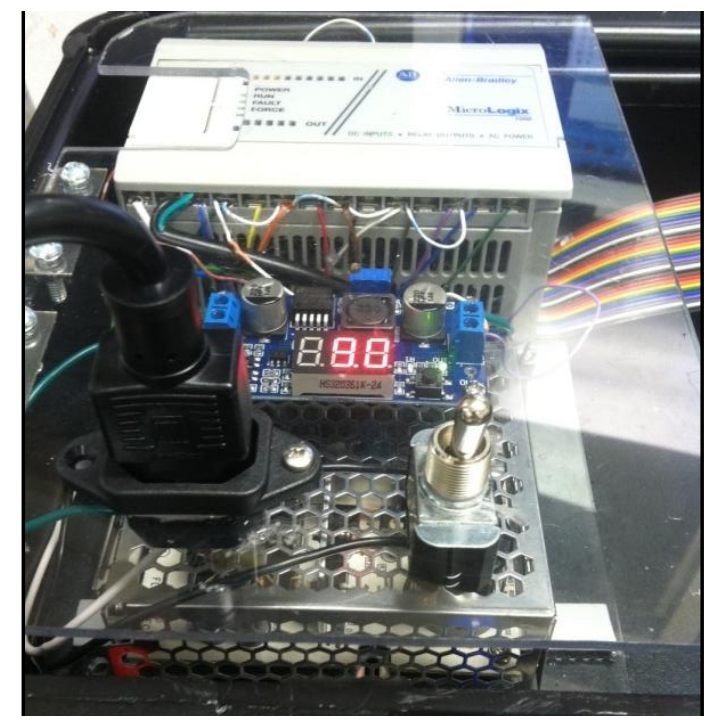

Figure 1: Power Supply Unit for Micrologix 1000 PLC

\subsection{Design of the Miniaturize Automated Color Sorting System}

Before any programming and construction could begin for the system, the design process needed be completed. Originally, it was best to design the system using the program SoildWorks, but because time was limited for this research project, hand sketches were made for the system instead. Initially, the only products that were available were products from Fischertechnik. Fischertechnik is a flexible construction system for children young and old that includes product sets that are used for play, in education, and in industry for design and simulation. One of the main objectives of the system was to be as complex as possible. Because of constraints, the complexity of the system was limited. Constraints included the following: 8.5 " $\mathrm{x} 5$ " $\mathrm{x}$ " of space to construct the system on, the parts available to use, and the number of inputs/outputs that could have be used. These constraints caused the system go through two different designs. Design B became the final design of the system.

\subsubsection{Design A}

To begin with the design process, the input of the system was designed first then the method of distinguishing the color of the marbles follows. The initial idea was to use a $76.2 \mathrm{~mm}$ PVC or acrylic tube with a diameter of $15.9 \mathrm{~mm}(5 / 8$ ") to hold and stack the red, green, and marbles that were $12.7 \mathrm{~mm}(1 / 2 ")$ in diameter for the system. The tube will be placed in the front of the system and will be elevated a couple of inches on top of a couple of Fischertechnik building blocks. By leaving a bit of space between the tube and the building box, a solenoid actuator, which will be powered with 9VDC, could be used to push the marbles into a desired part of the system. The solenoid actuator will be placed to the right of the tube in order to push the bottom marble of the stack one by one. In order to detect the color of the marble, a color sensor was needed. Since the Micrologix PLC 1000 can detect highs and low, a color sensor was needed that didn't incorporate extra hardware for image processing. After searching the web, a color sensor called the QC50 Series True Color Sensor made by Banner was the best choice for the system. The easy-to-use QC50 series true color sensor uses modulated white light with red, green, and blue (R, G, B) electronic filters to scan for the presence of one, two or three colors. Its compact size allows it to be mounted almost anywhere. Configuration options include Programming mode for color detection parameters and Setup mode for selecting an adjustable output OFF-delay or selecting between two response speeds (some models). Three solid-state outputs may be set individually for color differentiation or for color-plus-intensity differentiation. The sensor has two push buttons, Set and Select, plus a 4-digit LED display, an Output LED, and three Output Status LEDs (one for each sensing output), for easy programming and status monitoring during operation. Since the color sensor is powered with $24 \mathrm{VDC}$, when it detects a Color that it was programmed to detect, it will energize a certain colored wire providing 24VDC (High). This was a perfect use for the PLC. This color sensor will be placed directly in front of the colored marbles in order to detect each marble one by one.

After the design of the input and detecting stage of the system was completed, the design for the separation of the marbles by their color then took place. In order to distribution the marbles through the system, the idea of using a straight chain belt worked best for this design. The chain belt will be consisted of Fischertechnik products such as; chain links to construct the $464 \mathrm{~mm}$ chain belt, $2 \mathrm{cog}$ wheels to rotate the chain belt, a 9VDC motor and gear box, four $30 \mathrm{~mm}$ clip axles to hold the 
cog wheels, and building blocks for structure. The chain belt will be at the same height as the first solenoid actuator in order for the marble to be pushed onto the moving chain belt. In order to separate the colored marbles while they move down the moving chain belt, the idea of using 2 more solenoid actuators to pull marbles off the chain and into chutes was conceived. These solenoid actuators will have some type of flat hook in order to pull the marbles off the moving chain belt. There will be three chutes in order to separate the marbles by their colors. The first chute for the red marbles will be constructed on the right middle side of the chain belt while the second and third chute will follow right behind. The second chute will be used for the green marbles while the third chute will be used for the blue marbles. The red and green marbles will be pulled into their chutes by having each solenoid actuator constructed high enough above each chute in order to pull the marbles. For the blue marbles, an angled piece at the end of the chain belt will be used in order for the blue marbles to fall into the last chute after moving down the moving chain belt. All these chutes will then be connected to provide a new input to the system. These chutes will be made out of PVC or acrylic tubing. In order to let the PLC know when a marble is approaching the solenoid actuator to pull the marble off the chain belt, sensors will be needed. Fischertechnik provides sensors that work with a phototransistor and light bulbs that can be powered with 9 VDC. The phototransistors will be separately connected to its own compact 5VDC/1A SPST Reed Relay. Since the PLC cannot detect any voltage below 14 volts, the relays will be needed in order to send out 24 VDC to the PLC when the sensor is tripped. As light emits onto the phototransistor, 24 volts drops across the PLC while connected. If no light emits onto the phototransistor, no voltage will be dropped across the PLC. These sensors will be placed behind the first and second solenoid actuators. By providing a wall to the left of the moving chain belt, phototransistors will be placed against that wall while the light bulbs will be placed parallel to the phototransistors.

After the design of the separation of the marbles by their colors was completed, the design of randomizing the colored marbles to become a new input for the system then took place. The idea of using a small funnel to input the marbles into a rotating drum for randomization was then conceived. A small drum with the diameter of about $40 \mathrm{~mm}$ and $60 \mathrm{~mm}$ will be used to randomize the colored marbles. A stand will also be provided made of acrylic sheets to hold the drum in place as it rotates. In order to rotate smoothly, 2 ball barriers will be attached at each end of the drum while a 9VDC Fischertechnik powers a rotating wheel underneath the drum which will cause the drum to rotate in a clockwise direction. The drum will also have two openings on each in and will be placed at a downward angle in order for the marbles to drop out of the drum after being randomized. In order for the PLC to detect marbles reaching the drum, another sensor using a phototransistor and bulb will be placed in front of the funnel. Therefore, when marble trips the sensor, the motor for the drum will be energized.

To transfer the new input coming out of the drum back into the input tube, an inclined conveyor will be constructed. The conveyor will consist of Fischertechnik products such as; a $120 \mathrm{~mm}$ chain belt, two $120 \mathrm{~mm}$ I-struts with bores, two 60 mm clip axles, two cog wheels, a 9VDC motor with a gear box, (x) black step pieces attached to the chain belt, and a couple of building blocks for structure. Another sensor will be placed before the conveyor in order to let the PLC know when to energize the motor that controls the conveyor belt in order to move the marbles upward. As the marbles fall out of the rotating drum, they will land into the conveyor and will travel to the top to drop into the input tube. This will then end one cycle of the system and continue until a user turns off the system. A sketch of Design A is provided below in Figure 2.

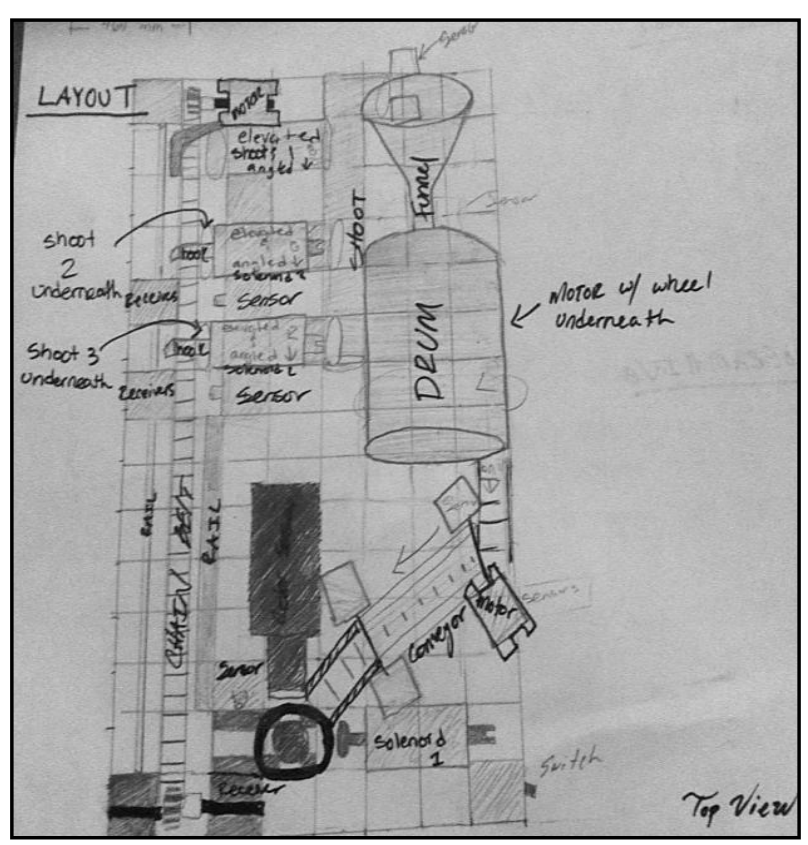

Figure 2: Top View of Design A (Drawn to Scale)

\subsubsection{Design $B$}

Design B was created as a backup design if Design A was not successful. Design B consisted of the design changes of separating the marbles, the drum design, and the input of the system. The inclined conveyor design would also be altered.

Instead of using solenoid actuators with hooks attached to pull the marbles off the moving chain belt, gates can be attached to the solenoid actuators instead. In order for the gate design to be successful, the moving chain belt will need to be constructed by raising the left side of the chain belt by 60 degrees. By constructing the chain belt in this manner, the chain belt will be leaning to its right in order for the marbles to move down the chain belt without falling, a wall, made out of acrylic sheet, will be constructed to the chain belt's right side to provide support for the marbles. This wall will also have two small openings that are big enough for a marble to fall through. These openings will be used to place a gate in its place. By attaching a small square piece from an acrylic sheet to the end of the solenoid actuators, it will be used to open and close the opening in the wall. These gates will be initially positioned in order for the wall to be a complete wall. The purpose of the gates' initial position will be for the blue marbles to travel down the chain belt so they will not become stuck by any of the gates. As mentioned before in sub-section 3.2.1, as a red or green marble trip their sensor, a solenoid actuator will be energized. In this design, when a marble is moving down the chain belt and trips their sensor, a solenoid actuator will be energized to pull down the square acrylic piece and let the marble fall into the opening and into the desired chute. Only two sensors, not including the color sensor, will be used for this design.

Instead of using a drum stand made out of acrylic sheets to hold the drum in place while it rotates, a 3-D model can be created and printed using the program SolidWorks. The CAD model of the design is shown below in Figure 3. 


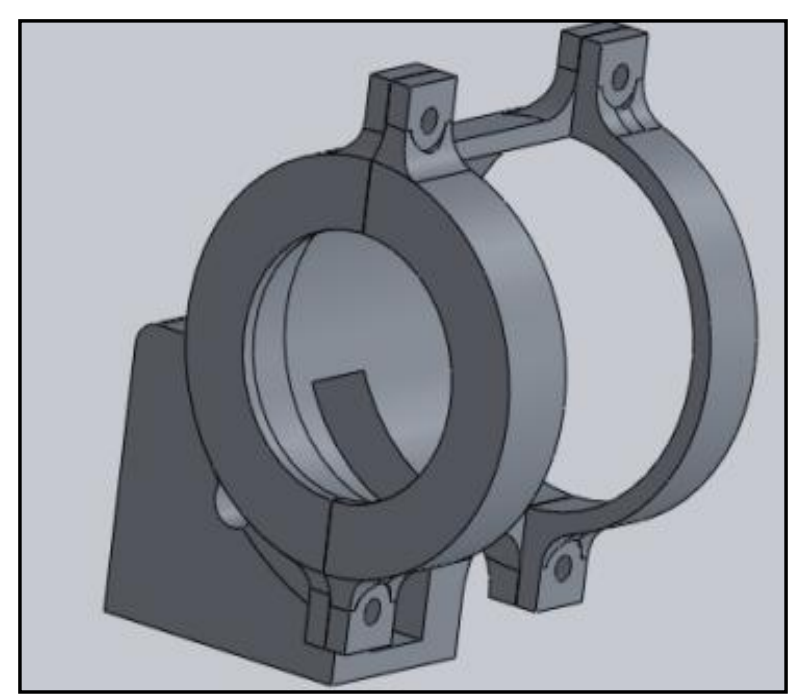

Figure 3: CAD Model of Drum Stand

The dimensions of this design were based off the drum that will be made by an old Advil medicine bottle. This design also includes the space for one ball barrier that will be attached to the narrow part of the drum. In order for the drum to rotate, a $60 \mathrm{~mm}$ clip axle and a small wheel with a diameter of $23.8 \mathrm{~mm}$ will be used underneath the drum. The small wheel will be powered with a 9VDC motor just as in Design A. As seen in Design A, a funnel would be used to input the balls into the drum, but for this design, an extra chute will be used instead. Also the inclined conveyor will be positioned directly in front of the drum instead of at a 45 degree as in seen in the previous design.

Instead of using PVC or acrylic tubing for the input, the new drum will act as the new input. This will be easier to input a handle full of colored balls into the system if they are first randomized by the drum and moved by the inclined conveyor. Because of the tubing not being used, an alternative way needed to be design for the color sensor to detect the color of the marbles. A declined chute will be provided at the output of the inclined conveyor in order for the marbles to roll down in front of the color sensor to be detected and land in a position for the first solenoid actuator to push the marble into the moving chain belt. A sketch is not provided since theses design changes were made after the construction of the Design A.

\subsection{Ladder Logic Programming using RSLogix 500 Pro}

Before any construction could begin, programming had to be completed. To communicate with the Automated Color Sorting system, the Allen-Bradley Micrologix 1000 PLC was programmed with ladder logic using the program RSLogix 500 Pro. This Micrologix 1000 PLC that was used has 10 inputs and 6 outputs to communicate with a system. In order for different outputs to be energized, timers and latches were used in the RSLogix 500 Pro ladder logic program. Ladder logic programming is similar to "IF" and "ELSE" statements, which made this type of programming easy to learn and use.
The following include the problem statement, determination of I/O Ports and the operation sequence needed before the construction of system; Problem Statement: To create a continuous system by sorting colored marbles into groups by their color then randomize the output which is then fed as a new input for the system.

Table 1: Description of I/O Ports

\begin{tabular}{|c|c|c|c|}
\hline $\begin{array}{c}\text { Inputs } \\
(\mathbf{I} / \mathbf{X})\end{array}$ & Description & $\begin{array}{c}\text { Output } \\
(\mathbf{O} / \mathbf{X})\end{array}$ & Description \\
\hline $\mathrm{I} / 1$ & Sensor 1 & $\mathrm{O} / 0$ & $\begin{array}{c}\text { Solenoid1 } \\
\text { Push Marble }\end{array}$ \\
\hline $\mathrm{I} / 2$ & Sensor 2 & $\mathrm{O} / 1$ & $\begin{array}{c}\text { Solenoid2 } \\
\text { Red Gate }\end{array}$ \\
\hline $\mathrm{I} / 3$ & Sensor 3 & $\mathrm{O} / 2$ & $\begin{array}{c}\text { Solenoid3 } \\
\text { Green Gate }\end{array}$ \\
\hline $\mathrm{I} / 5$ & $\begin{array}{c}\text { Color Sensor } \\
\text { Red }\end{array}$ & $\mathrm{O} / 3$ & $\begin{array}{c}\text { Motor1 With } \\
\text { Parallel Light }\end{array}$ \\
\hline $\mathrm{I} / 6$ & $\begin{array}{c}\text { Color Sensor } \\
\text { Green }\end{array}$ & $\mathrm{O} / 4$ & $\begin{array}{c}\text { Motor2 With } \\
\text { Parallel Light }\end{array}$ \\
\hline $\mathrm{I} / 7$ & $\begin{array}{c}\text { Color Sensor } \\
\text { Blue }\end{array}$ & $\mathrm{O} / 5$ & $\begin{array}{c}\text { Motor3 With } \\
\text { Parallel Light }\end{array}$ \\
\hline $\mathrm{I} / 8$ & Switch 1 & N/A & N/A \\
\hline $\mathrm{I} / 9$ & Switch 2 & N/A & N/A \\
\hline
\end{tabular}

Table 2: Operator Sequence of System

\begin{tabular}{|c|c|}
\hline Step 1 & $\begin{array}{c}\text { If SWITCH1 is pushed, Energize Motor2 (with } \\
\text { pulse) AND Motor3 (START PROGRAM) }\end{array}$ \\
\hline Step 2 & $\begin{array}{r}\text { IF SWITCH2 is pushed, De-Energize Motor2 } \\
\text { and Motor3 }\end{array}$ \\
\hline Step 3 & $\begin{array}{c}\text { If Color Sensor detects R, G, OR B, Energize } \\
\text { Solenoid1 after 2 seconds AND Motor1 }\end{array}$ \\
\hline Step 4 & $\begin{array}{c}\text { If Color Sensor detects RED and Sensor1 is } \\
\text { tripped, Energize Solenoid2 for 2 seconds }\end{array}$ \\
\hline Step 5 & $\begin{array}{c}\text { If Color Sensor detects GREEN and Sensor2 is } \\
\text { tripped, Energize Solenoid3 for 2 seconds }\end{array}$ \\
\hline Step 6 & $\begin{array}{c}\text { If Color Sensor detects BLUE and Sensor2 is } \\
\text { tripped, De-Energize Motor1 after 1 second }\end{array}$ \\
\hline Step 7 & $\begin{array}{c}\text { If Sensors 1,2 are tripped, De-Energize Motor1 } \\
\text { after 1 second }\end{array}$ \\
\hline Step 1 & $\begin{array}{c}\text { If SWITCH1 is pushed, Energize Motor2 (with } \\
\text { pulse) AND Motor3 (START PROGRAM) }\end{array}$ \\
\hline IF SWITCH2 is pushed, De-Energize Motor2 \\
and Motor3
\end{tabular}




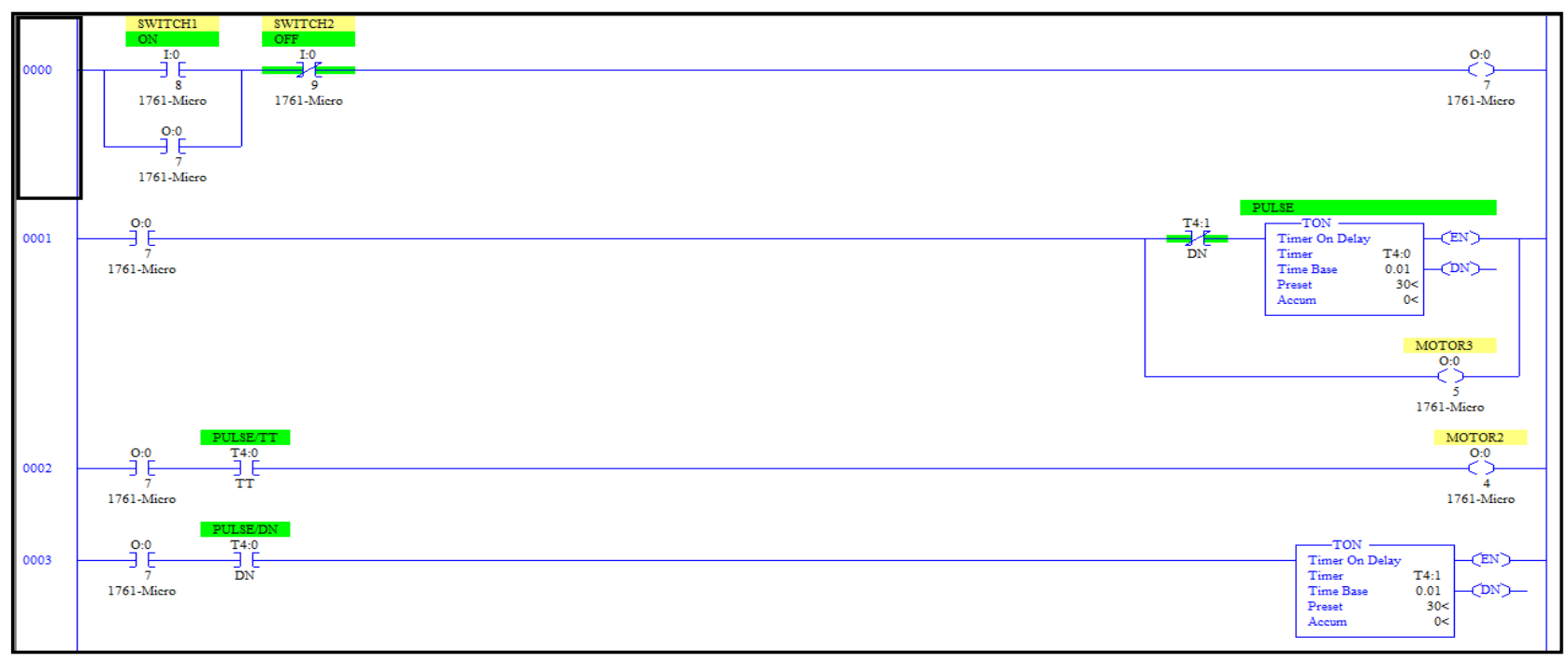

Figure 4: Ladder Logic for Switches $1 \& 2$ and Motors $2 \& 3$

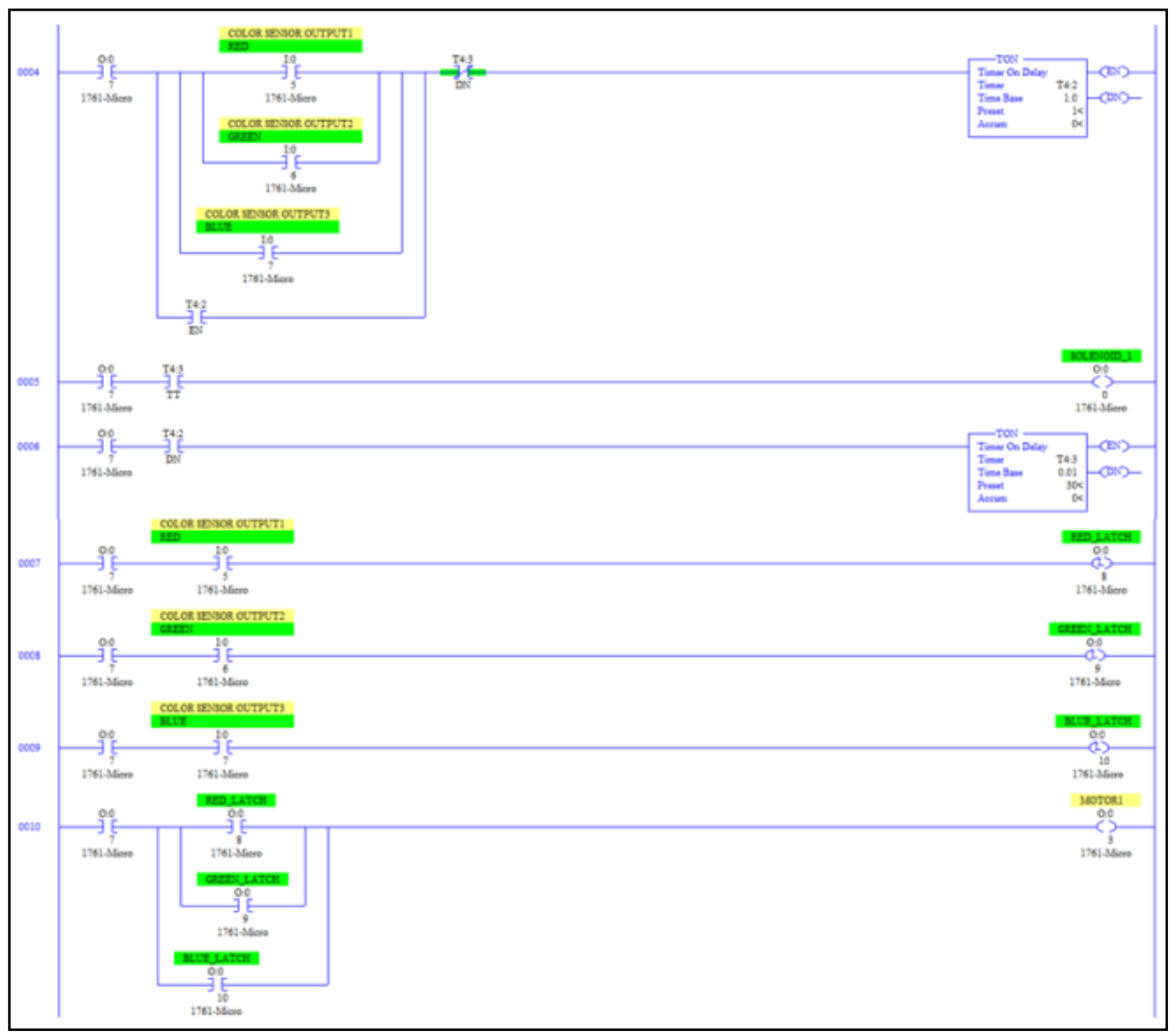

Figure 5: Ladder Logic Program of Color Sensor Outputs, Solenoid 1, and Chain Belt Motor 


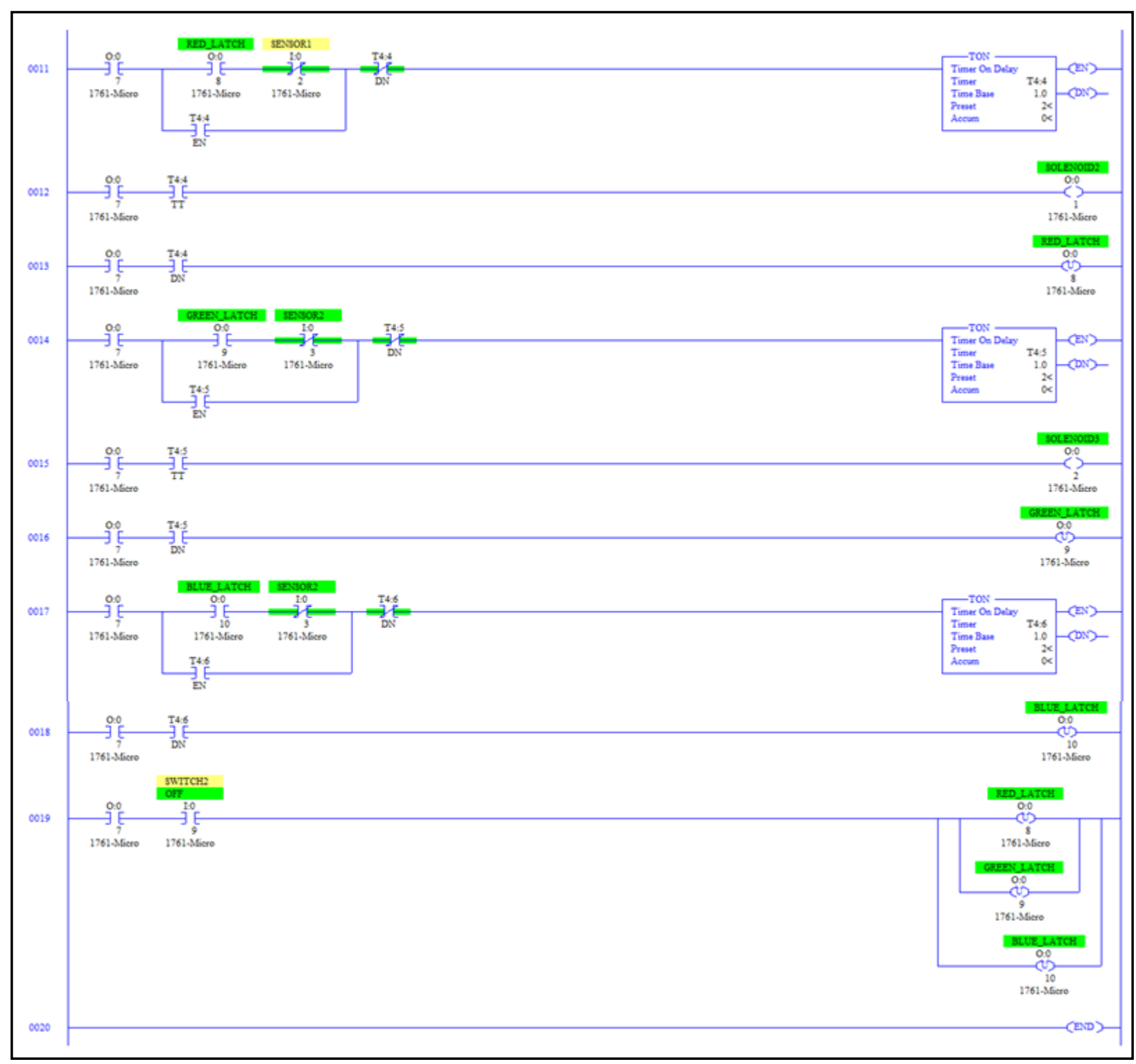

Figure 6: Ladder Logic for Phototransistor Sensors

After the determination of $\mathrm{I} / \mathrm{O}$ ports and operation sequence was completed, ladder logic programming could now be developed. As seen in Figure 4, the beginning of the ladder logic is shown. The functions in the programmed have to declare an address in order to work with a certain I/O port. For example, Switch 1's address was I: 0/9. The "I" determines an input, " 0 " determines the PLC and " 9 " determines the input port. Lines 0000-0003 show step 1 from the operation sequence: If SWITCH1 is pushed, Energize Motor2 (with pulse) AND Motor3 (START PROGRAM). For switch 1, an "Examine if open" function was used and an "Examine if closed" function was used for switch 2. Switch 2 is used for Step 2 of the operation sequence: IF SWITCH2 is pushed, De-Energize Motor2 and Motor3. In order for the motors 2 and 3 to stay energized, an "Examine if open" function was used in parallel of switch 1. A dummy bit was used at the end of line 0000 to provide some organization to the program. The parallel "Examine if open" function used the same address as the dummy bit. When the switch1 is pushed, it will become true and energize the dummy bit output. Since the output was energized, it will turn the parallel "Examine if open" function true as well. Even if the user stops pressing the switch, the dummy bit output will stay energized until Switch
2 is pressed which will then make the line false. In beginning of lines 0001-003, the dummy bit's address is used on 3 other "Examine if open" functions in order to start the timers "TON" at line 0001 and 0003 to energize Motor 2 off and on to create the desired pulsing of the drum. Motor 3 was directly energized to keep the inclined conveyor at a constant speed. PULSE/TT in line 0002 and PULSE/DN were used to know when to turn Motor 2 off and on every 0.3 seconds. The dummy bit was used at the starting of every programming in order to stop every function throughout the program when Switch 2 is pressed.

After the ladder logic for switches $1 \& 2$ and motors $2 \& 3$ were completed, the ladder logic program for the color sensor outputs, solenoid actuator1, and the chain belt motor could now be developed. As seen in Figure 5, line 0004 shows if Color Sensor Output 1 (Red) or Color Sensor Output 2 (Green) or Color Sensor Output 3 (Blue) becomes true, energize Solenoid after 2 to push the marble onto the chain belt. As seen in lines 0007-0010, latches are used for the programming of the sensors later on in the program. The reason for the latches was for the system to know when a colored marble fell into the desired chute in order to de- 
energize the motor of the chain belt. This will be explained later on when the programming of the sensors are discussed. Step 3 of the operation sequence is used for this part of the program: If Color Sensor detects R, G, OR B, energize Solenoid1 after 2 seconds AND Motor1.

The next part of the program was for the phototransistor sensors. When the system was powered on, the bulbs were always emitting light to the phototransistor. This was always proving a voltage across the PLC output terminals. The sensors can be represented as "Examine if closed" functions in the ladder logic program. If a marble trips the sensor, no voltage drop will be seen. In other words, the sensor became "closed". As seen in Figure 6 in lines 0011, 0014, and 0017, if a red, green, or blue latch become true (detected by the color sensor) and a certain sensor is tripped/"closed", then energize the desired solenoid for 2 seconds. If a red marble was detected and the first sensor was tripped, solenoid 1 was energized for two seconds to open its gate. If a green marble was detected and the second sensor was tripped, solenoid 2 was energized to open its gate just as the pervious solenoid. If a blue marble was detected and sensor 2 was tripped, motor 1 was de-energized for the chain belt. As mentioned previously, when any sensor was tripped, motor 1 will de-energize after 2 seconds. Line 0019 used de-latch functions for any motors that were energized before pressing switch 2 to be de-energize when turning back on the system. Step 4-7 from the operation sequence was used for this part of the programming. After the programming was completed, construction could then take place.

\subsection{Construction of Design A \& B}

The construction of Design A had its pros and cons. The pros of Design A were the chutes and the inclined conveyor. Each chute successfully moved the marbles down towards the rotating drum and the inclined conveyor successfully carried the marbles upwards towards the position of the color sensor. The cons of Design A were the rotating drum, the input tube, and the moving chain belt with the solenoid actuator hooks. By cutting a hole with the same diameter as the ball barrier for the drum, the drum with the barrier was pushed into the hole in order for the ball barrier to not move. This allowed the drum to rotate freely without the ball barrier moving. In order for a wheel to spin the drum underneath, a small hole below the larger hole was drilled for a wheel axle. A 9 VDC motor was attached to the axle where the axle was pushed through the hole before attaching a wheel at the end. This allowed the wheel to spin the drum when the motor was energized. The drum rotated, but very slowly. Instead of using the Fischertechnik motor, a Chinese DC Motor was used instead. This motor was much stronger than the Fischertechnik motor and spun the drum at a good rate. Enough the design worked, it was unprofessional looking and too bulky to add to the system. The design of the drum was not used. Instead of using this design, the 3-D part for the drum stand was created and printed. By attached the Chinese DC motor to an axle and a wheel, the drum successfully spun at a steady pace and the design of the drum stand fit perfectly in the system. This design was not bulky and professional looking. Next, the input tube design had some problems. Since construction space of the system was constricted, getting the marbles back to the input was very difficult. Instead of standing the tube straight up, the design idea of heating and bending the acrylic tube at almost a 90 degree angle was conceived. By having the input of the tube at the top of the inclined conveyor and the output of the tube in front of the color sensor, the design was thought that it could be successfully, but on the contrary, it was not. Bending the acrylic tube at an almost 90 degree angle was very difficult. Even if the tube was bent at this angle, the inside diameter would be compromised and the marbles would not run through. Instead of using this design, the simple design from Design A was used by using chutes to let marbles fall down and in front of the color sensor. Also, the new input would now be the rotating drum instead of the input tube. The next con was the moving chain belt and the solenoid hooks. The moving chain belt was successful, but the design of the solenoid actuator hooks was not. Creating hooks on the solenoid actuators was difficult and not reliable. Even if the design of the hooks were created, the system would have had a difficult time pulling the marbles into the provided chutes. Another method for the solenoid actuators was then needed. Instead of using hooks, square pieces from an acrylic sheet were glued to the end of the solenoid actuators to act as a gate. This was Design's B method of the solenoid actuators. In order for the gates to work properly, the construction of the moving chain belt had to be altered. As written in Section 3.2 .2 , the moving chain belt was constructed by raising the left side of the chain belt by 60 degrees. A wall, made out of acrylic sheet, was constructed to the chain belt's right side to provide support for the marbles as they moving down the leaning chain belt. This wall also had two small openings that were big enough for a marble to fall through. These openings were used to place a gate in its place. The design was successful and easier for the system to separate the colored marbles into their chutes. Overall, the construction of Design $\mathrm{B}$ was a better fit for the system. Figure 7 and 8 show the difference between designs. Note that in design A, the original drum stand was not placed into the system because of its bulky design.

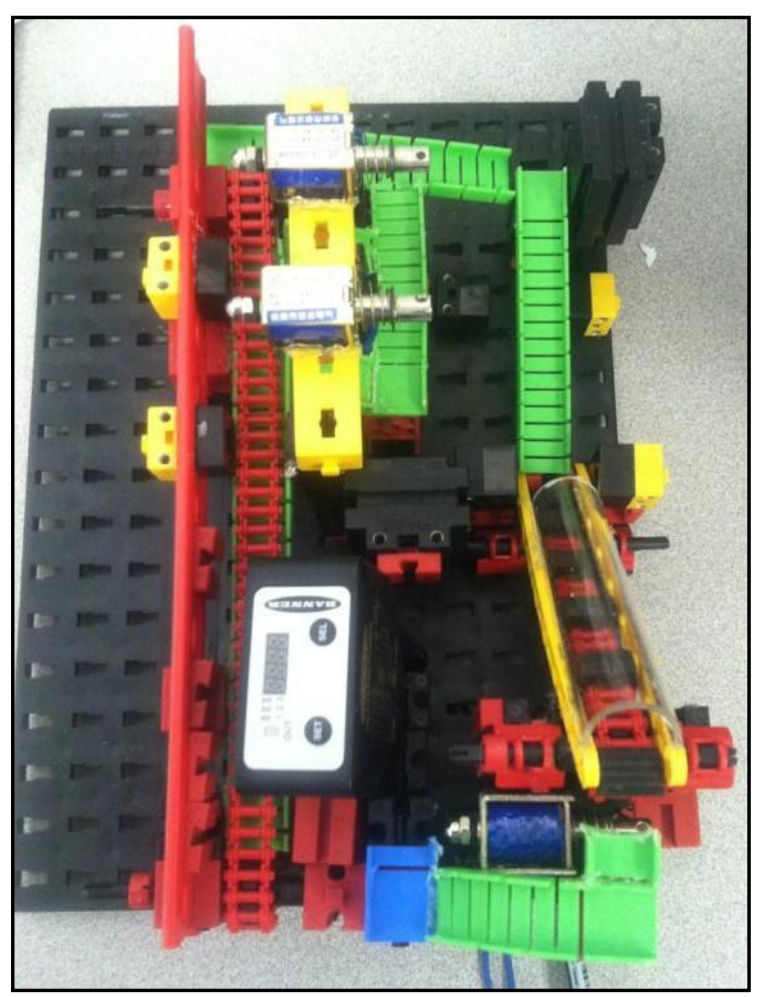

Figure 7: Top View of System with Design A 


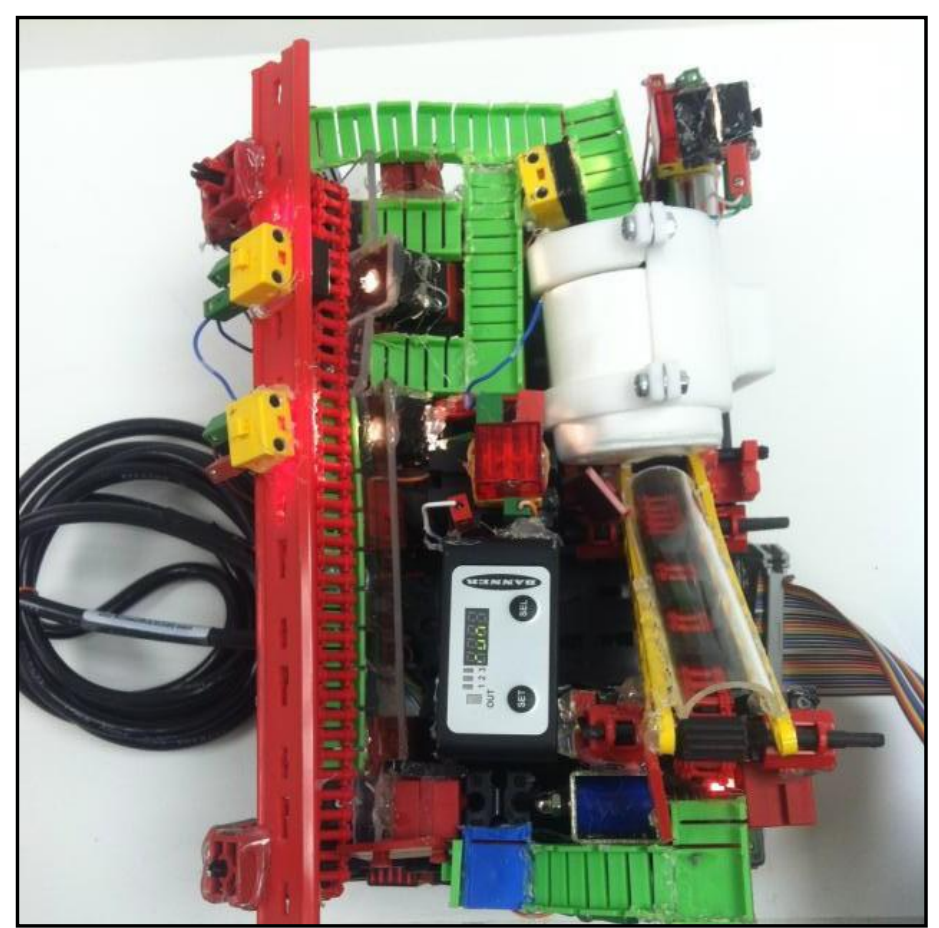

Figure 8: Top View of System with Design B

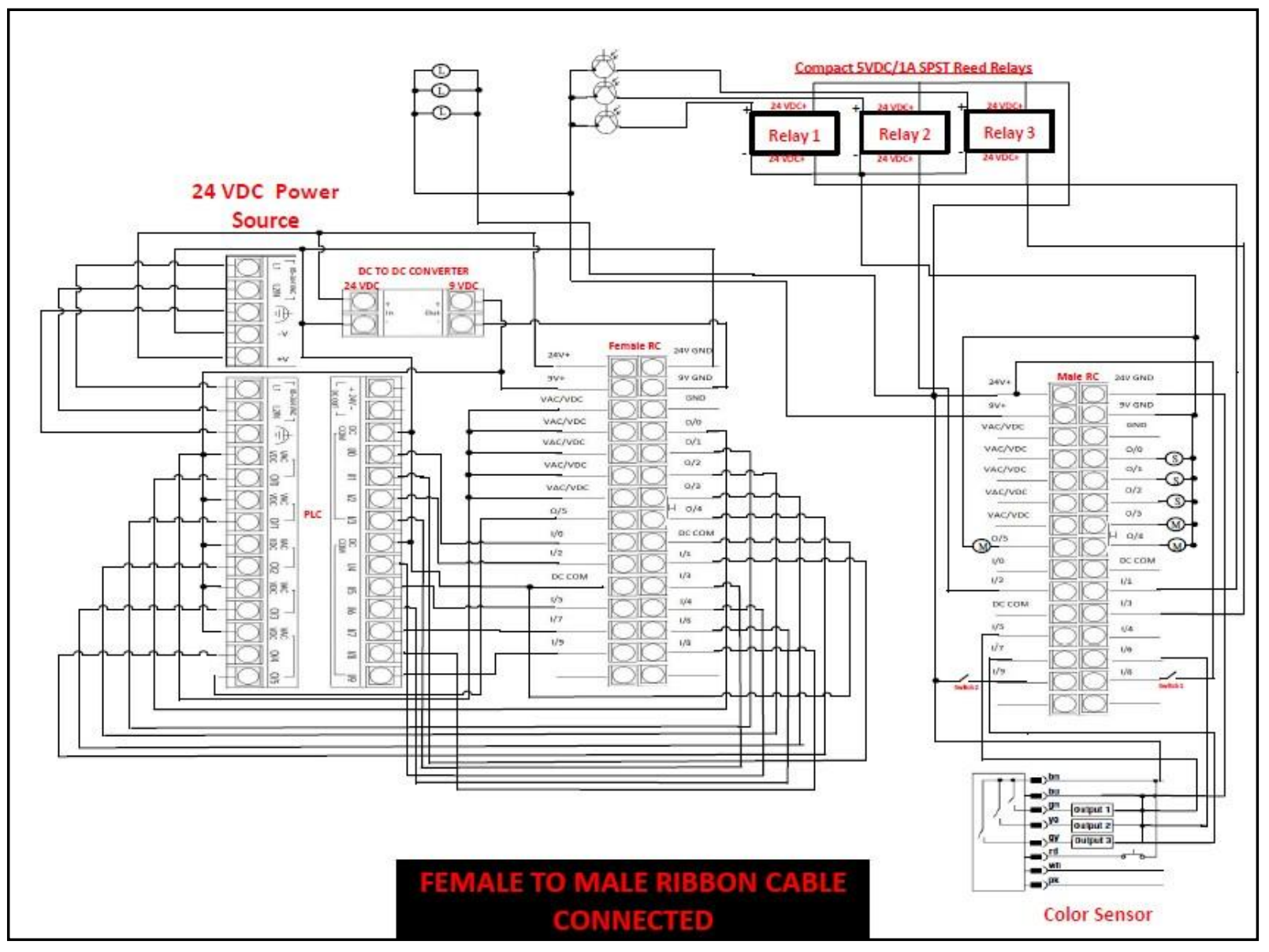

After the main construction stage was completed, the wiring of the system needed to be started. By using a female to male ribbon cable connector to communicate with the PLC, it was more convenient instead of directly wiring all inputs and outputs to the PLC terminals. By attaching a male connector to the side of the system, disconnecting and connecting the PLC from the system was fairly simple. After, wires were connected to all positive and negative terminals of the inputs and outputs. These wires were then soldered to the appropriate pin in order to communicate with the PLC. Figure 9 shows a 
representation of the wiring through a schematic.

Now that the wiring stage was done with the system, it could now be powered and communicate with the PLC. Figure 10 shows the miniaturized automated color sorting system connecting to the PLC and power sources.

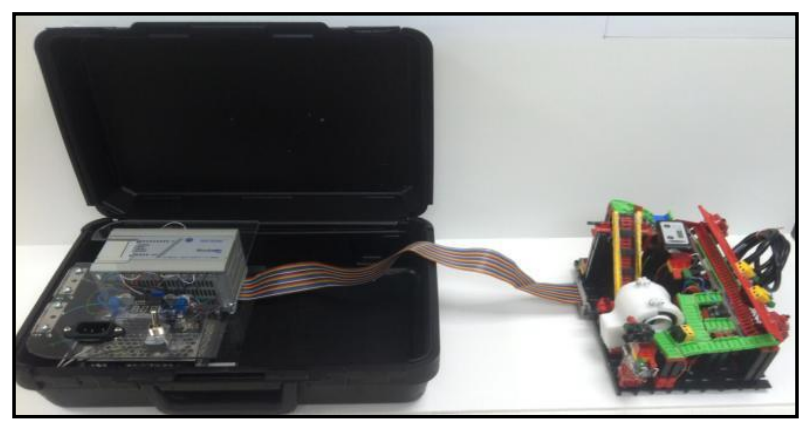

Figure 10: Wired Connection between PLC and System

\subsection{Design of Web-Based Server}

Now that the system was up and running, the web- based server could now be developed. The architecture utilizes the following Apache Server, HTML, PHP Script, VB application, ladder logic programming, and webcam server. The Apache Server hosted the web page, PHP script and the VB Application. Ladder Logic Program was used controls the automated system to perform the operation sequence. VB Application was used constantly check contents of an output file and communicates with the PLC. The HTML Web Page and PHP script allowed a remote user to click on a Start or Stop button. This will invoke a PHP script to write either 0 or 1 to the output file. The PHP script was used to write appropriate value to the output file. The webcam server had its own IP address which presented a live image of the PLCbased automated system to the user. The image is presented within a frame of the web page.

\section{DISCUSSION}

The construction of the Automated Color Sorting System took up the most time of this research. A successful running system needed to be working before it could be used for the WebBased Server. The system had some problems initially, but eventually they were solved. Due to the QC50 Series True Color Sensor, the color sensor would not detect the color of the marble at times which would then cause the system to not work properly. Overall, the construction of the system was successful. Communication with the Automated Color Sorting System using the Apache Based Server was also successful. By using the VB application, there was a constant check of the contents of an output file which communicated with the Micrologix 1000 PLC. When the content was"1", the program would send an input bit of 1 (force input 1 to be true) to the PLC; then the system would run. If the content was " 0 ", the program would send an input bit of 0 (force input 1 to be false) to the PLC and then the system would stop running.

\section{ACKNOWLEDGMENTS}

This material is based upon work supported by the Research Experiences for Undergraduates Program under National Science Foundation Grant No. 1263293. Any opinions, findings, and conclusions or recommendations expressed in this material are those of the author(s) and do not necessarily reflect the views of the National Science Foundation.

\section{REFERENCES}

[1] Q. Lu, S. Srikanteswara, W. King, T. Drayer, R. Conners, E. Kline, P. Araman, "Machine Vision System for Color Sorting Wood Edge-Glued Panel Par," Virginia, 1997.

[2] Ren C. Luo, Wei Zen Lee, Jyh Hwa Chou , and Hou Tin Leong, "Tele-Control of Rapid Prototyping Machine Via Internet for Automated Tele-Manufacturing," Taiwan, 1999

[3] Sanjay B. Joshi and Mark R. Supinski, "The development of a generic PC-based programmable logic controller simulator," Pennsylvania, 1991Tavel, P. 2007 Modeling and Simulation Design. AK Peters Ltd.

[4] Darko Todorović, Zoran Jovanović, Goran S. Đorđević, "Monitoring the PLC based Industrial Control Systems through the Internet using Microsoft Robotics Developer Studio Technologies," Serbia, 2011

[5] Darshil, Sagar, Rajiv, Satyajit A. Pangaokar, and V.K. Sharma, "Development of a PLC Based Elevator System with Colour Sensing Capabilities for Material Handling in Industrial Plant,"Alandi," Pune, 2008

[6] Zafer Aydogmus, Member, IEEE, and Omur Aydogmus, Student Member, IEEE, "A Web-Based Remote Access Laboratory Using SCADA,” Turkey, 2008

[7] Handy Ali Munir, Nordin Saad, Syed Alwee Aljunid Syed Junid, Ahmad Mujahid Ahmad Zaidi, Mohd Zuki Yusoff \& Azhar Jaffar, "Real-Time Communication Between Personal Computer And Programmable Logic Controller For Networked Control System Based On Industrial Ethernet," Universiti Telnologi PETRONAS, National Defense University of Malaysia, 2010

[8] http://en.wikipedia.org/wiki/Programmable_logic_contro ller

[9] MengChu Zhou, Senior Member, IEEE, and Edward Twiss, Member, IEEE, "Design of Industrial Automated Systems Via Relay Ladder Logic Programming and Petri Nets," New York, 1998

[10] Ramnath Sekar \& Sheng-Jen Hsieh \& Zhenhua Wu, "Remote diagnosis design for a PLC-based automated system:1-implementation of three levels of architectures," London, 2011

[11] Sheng-Jen Hsieh, Patricia Yee Hsieh, "Web-Based Modules for Programmable Logic Controller Education," Computer Applications in Engineering Education, 13 (4), 2004, pp. 266-279. 